\title{
Structural knowledge in the homage tower of the alhambra palace
}

\begin{abstract}
The balancing of horizontal reactions has been a challenge in the construction of arches and domes throughout history, especially while using materials lacking tension capacity. This paper aims to analyze the level of structural knowledge of the designers at the time of the Nazarian Kingdom of Granada. A detailed study of the tributary loads acting on each dome and arch of the Homage Tower of the Alhambra Palace has been carried out. Evidence found in the distribution of domes, arches and openings in the walls has lead us to conclude that geometry of the tower was based on complete structural conception.
\end{abstract}

Volume 2 Issue $6-2017$

\author{
Bird JC, ${ }^{2}$ Gil-Martín LM,' Hernández-Montes \\ E, I,2 Salm RL, ${ }^{2}$ Patel TH² \\ 'Department of Civil Engineering, University of Granada, Spain \\ ${ }^{2}$ Department of Civil Engineering, Santa Clara University, USA
}

Correspondence: Hernández-Montes E, Department of Civil Engineering, Santa Clara University, USA,

Email emontes@ugr.es

Received: March 25, 2017 | Published: June 14, 2017

\section{Introduction}

The Alhambra Palace acted as both a palace and fortress for the Moorish monarchs during their rule of the kingdom of Granada, Spain. Construction primarily took place between 1238 and 1358. The Tower of Homage, a component of the palace, is a six-story masterpiece standing at 26 meters tall and served as the original entrance to the Citadel. This essay will aim to look at the Homage Tower specifically, analyzing how it was built with the primary concerns of horizontal thrust and tributary area in mind. Horizontal thrust of arches has been a concern throughout the history of construction. Several examples can be observed in Figure 1, from the stonecutters work in ancient Greece Figure 1A, Boyd ${ }^{1}$ where stones were placed in such a way that the horizontal thrust was resisted by friction, to the experiments of Leonardo da Vinci ${ }^{2}$ to measure it see Figure 1B, or the design of Brunelleschi in the dome of Santa Maria del Fiore where the horizontal thrust was solved by symmetry, balancing it at the corners of the octagon Figure 1C -see National Geographic. ${ }^{3}$

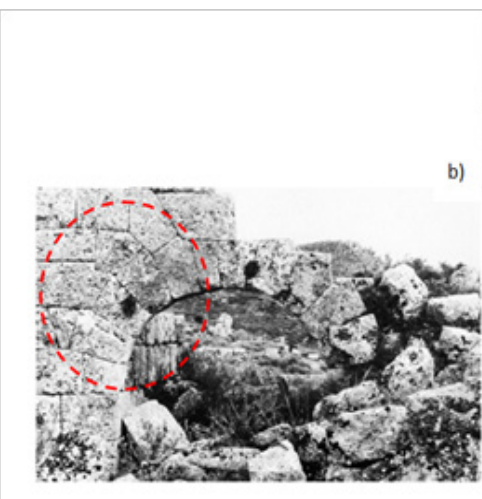

a)

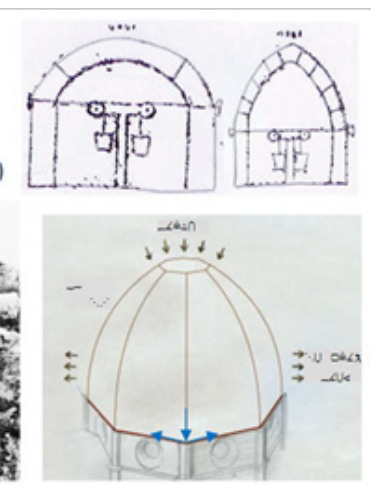

c)

Figure I A) Palairos fortification wall -adapted from Boyd 1978- B) Leornardo da Vinci experiment, C) Santa Maria del Fiore Dome, Florence, -adapted from National Geographic 2014.

\section{Arches in construction}

An arch is a man-made or natural structure which is held up entirely by compression forces. What is so special about the arch is that it does not need any tension in order to function. The arch is built by starting at the two bases. Carefully measured stones are placed in order to perfect the forces that allow the arch to function. False work holds up the two sides as they are being built. The keystone is the last stone to be placed, and it goes in the top middle of the structure. When the keystone is placed, the arch is able to support itself on its own. The forces within an arch largely stem from the weight of the arch. The weight is the stones themselves and the load they are carrying. The internal forces in the arch are inclined one to the other in order to balance this weight, see Figure 2. The thrust line of an arch is the path of the compressive force through the structure $\mathrm{F}_{1}$ and $\mathrm{F}_{2}$ in Figure 2, Romano \& Ochsendorf. ${ }^{4}$ The kernel is the center third of the arch see Figure 2. If the compressive force is located in the kernel, no tension will occur in the arch, i.e. when the thrust line is inside the kernel of the designed arch it is fully working in compression. The thrust line may also be called the "true arch." As it is understandable from Figure 2 , the horizontal component of the thrust force is constant along the length of the arch $\left(\mathrm{F}_{1} \cos \left(\alpha_{1}\right)=\mathrm{F}_{2} \cos \left(\alpha_{2}\right)\right)$, and the summation of the vertical components at the supports are equal to the weight of the arch.

Due to these components of the thrust force, a perfect semicircle cannot function as a true arch. In the case of perfect semicircles working as arches, only a vertical force at the base can exist because of their vertical tangent lines. As mentioned in the paragraph above, the horizontal force is needed and has to be greater than zero. There are several ways to discover the shape of "the true arch," or the line of thrust, inside of a designed arch: from analytical formulation Gil-Martín et al. ${ }^{5}$ to numerical approaches Alexakis \& Makris. ${ }^{6,7}$ Additionally, chain models may also give enough accuracy of "the true arch" shape, Hernández-Montes et al. ${ }^{8,9}$ In these models the hanging chain works entirely in tension, so by turning them into an arch the forces will begin to work entirely in compression. 


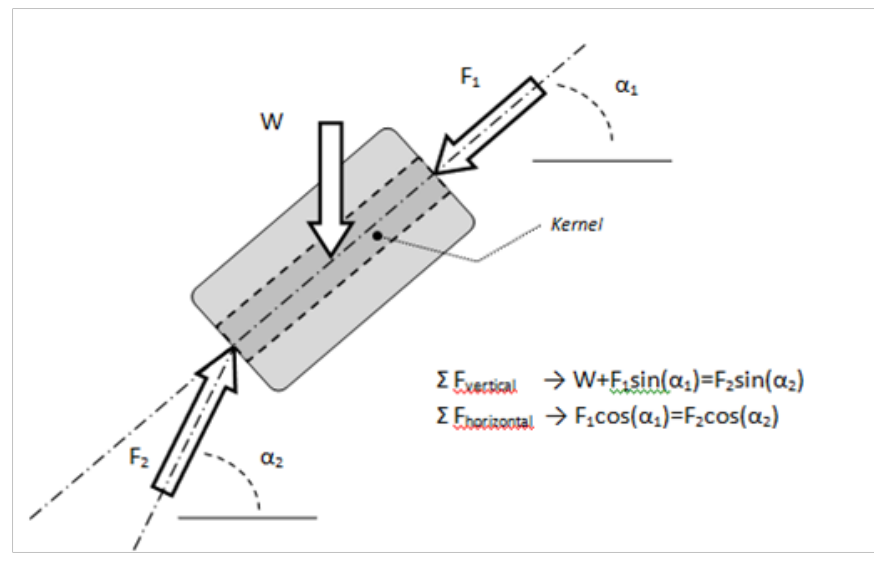

Figure 2 Inclination of the thrust line.

\section{Horizontal thrust}

The compressive force through the arch can be broken down into a horizontal and vertical component as shown in Figure 2. The vertical component is not of the same concern as the horizontal component because it does not threaten the structure's stability. It is resisted by vertical structural elements (walls, columns and foundations), which give it a large range weight that can be supported. In this case the upper limit is given by the material capacity.

The horizontal component of the thrust is most critical because it is difficult to balance. This component can cause an arch to fail if not supported, even if it is fairly small in comparison to the vertical component. Considering that an arch's entire structural integrity depends mainly on its ability to withstand the horizontal thrust, the compensation of that force is of optimal concern. There are several ways to balance the horizontal forces if materials with tension capacity are not used (such as ties, reinforcement,). Horizontal thrust has been dealt with in different ways including thick walls, the use of a buttress -and flying buttress-, and internal compensation of multiple arches. Thick walls are able to resist the horizontal thrust through friction due to their weight. Buttresses are external structural elements that resist the horizontal force by friction or working as a new arch that transmit the force to another element. Finally, horizontal thrust can be reduced by internal compensation see Figure 3, case 2 . It can be seen in Figure 3 that the main parameters affecting the horizontal thrust are the weight and the angle of the force at the supports. In order to analyze each one of the two horizontal thrusts in an arch, the weight is divided into tributary loads which affect each support see Figure 3.

By dividing the tributary load and reducing the angle of thrust at the supports, the designer is able to significantly reduce the horizontal thrust of the arch. Let us analyze case 1 in Figure 3, which has horizontal reactions equal to $\mathrm{R}_{1}$. Each support of the arch has a tributary load of $\mathrm{W}_{1}$ and the true arch has an angle with the horizontal equal to $\alpha_{1}$ at the origin of it. As can be seen in case 2 Figure 3, the magnitude of the horizontal reaction can be dramatically reduced by adding an additional support because it divides the tributary load atop each single arch in half, represented by $\mathrm{W}_{2}$. Furthermore, the resulting true arch shown in the figure exhibits a new, steeper angle $\alpha_{2}$ that further reduces the horizontal reaction. With the lightened tributary load and steeper angle, the horizontal thrust at the supports is reduced to $R_{2}$. As can be seen in the figure, the horizontal reactions of both arches at the internal support are compensated.
By equilibrium, the horizontal thrust in each one of the cases above considered can be calculated if the weight and the angle are known using the following equation:

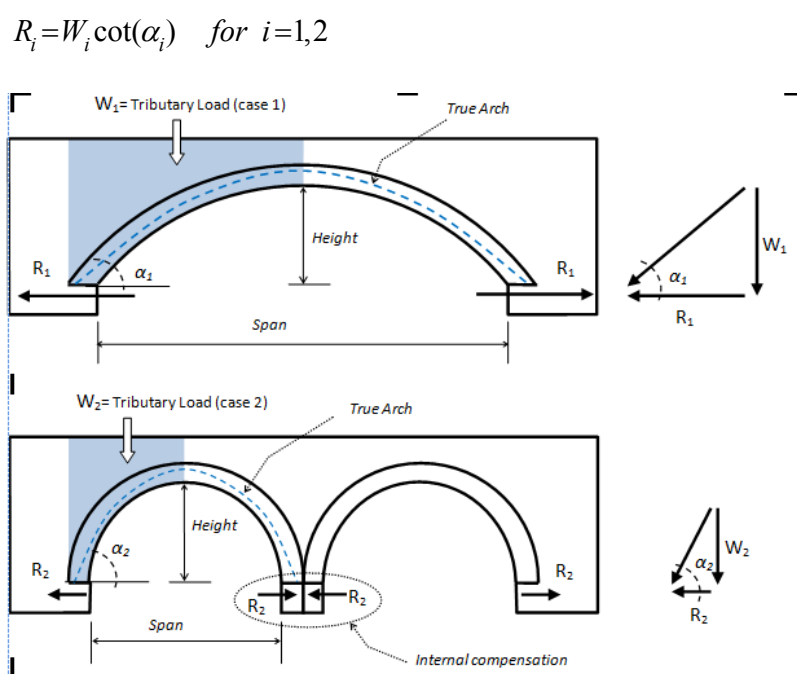

Figure 3 Reduction of the horizontal thrust.

\section{Homage tower}

The Homage Tower (13th Century) at the Alhambra Palace in Granada is a structural masterpiece in dealing with the compensation of the horizontal thrust; see Figure 4. Although it externally looks like a block, The Homage Tower is internally composed of six stories. Each story is composed of six domes and seventeen arches; the fifth story was studied in this piece of work. Four arches support each of these domes see Figure 4, but in entirety, seven arches are shared by two domes see Figure 5. The tower was constructed with fired bricks and no reinforcement. The main obstacle of the complex of domes and arches is to balance the horizontal thrust generated in each floor.

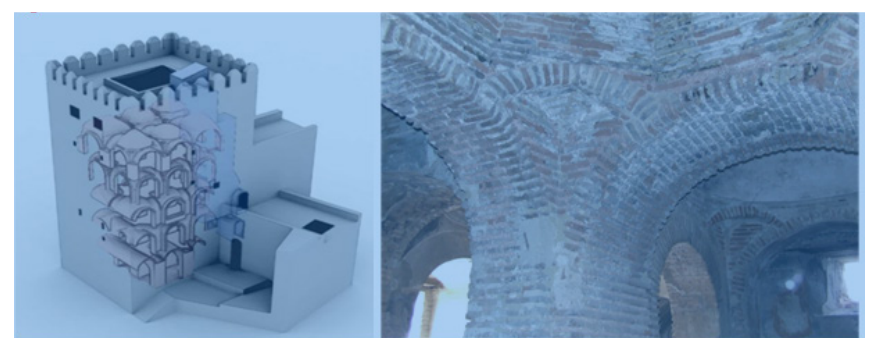

Figure 4 The systems for arches and domes in the Homage Tower. Adapted from Villegas (20I2).

There is equivalence between tributary load and tributary area. Figure 5 shows the tributary area weighing on one of the six domes. In order to distinguish between internally and externally balanced thrusts, each one of the tributary areas are divided into eight triangles; see Figure 6.

Following this division, the entire fifth story can be broken up into 48 triangles; see Figure 7. As can be seen, the horizontal thrust generated by 28 of these triangles are internally compensated, meaning that $58.33 \%$ of the overall horizontal thrust is internally balanced. The rest of the thrust, $40.67 \%$, has to be absorbed in the external walls by friction. The notion of non compensated horizontal thrust and the need of weight in the walls in order to equilibrate it by friction is further 
manifested in the distribution of openings (windows and the door). Five of the six openings are located in the lateral sides according to Figure 7 and only one is located in the bottom side. This would mean that the engineer who designed the Homage Tower in the Alhambra Palace must have been fully aware of how to reduce the horizontal forces resulting from the tributary load by balancing the load through strategic geometry. Therefore, the must have fully understood the concepts described prior to this section.
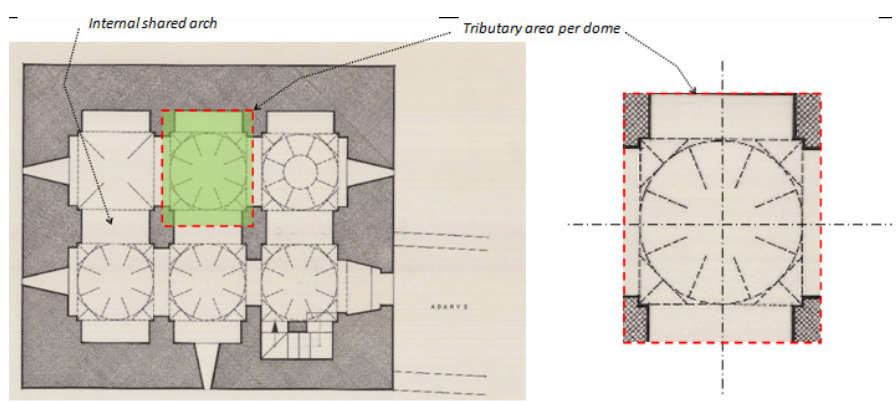

Plan view of the 5 th story

Figure $\mathbf{5}$ Tributary area of each dome.

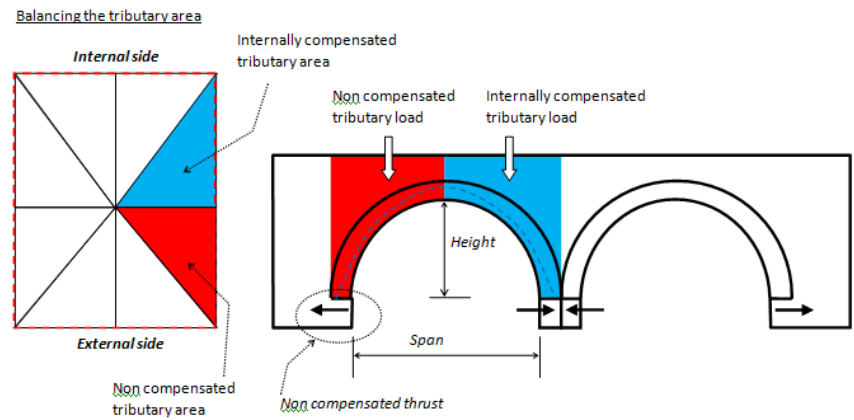

Figure 6 Balancing the horizontal thrust.

$$
\text { Division of the tributary area }
$$

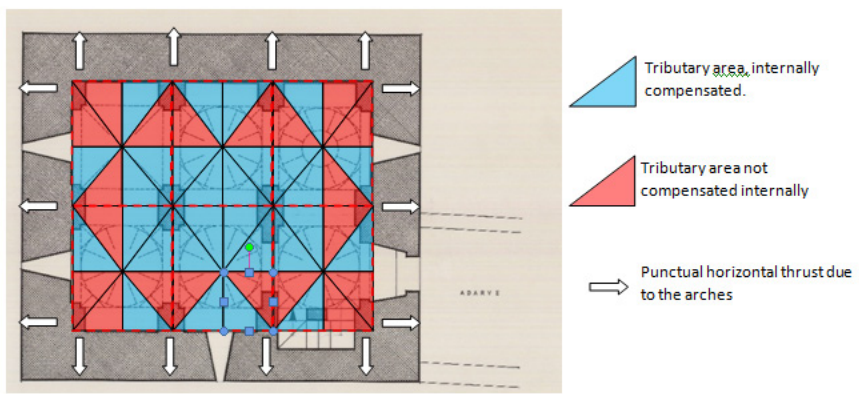

\section{Conclusion}

This piece of work analyzes the tributary load distribution in the Homage Tower of the Alhambra Palace, a military tower of 26meters high and six stories. It can be concluded that one aim of the design was to create each story with six domes and seventeen arches to reduce the horizontal thrust generated by the weight of the structure. The design of tower shows how great the structural knowledge of the engineers and designers was at that time.

\section{Acknowledgements}

None.

\section{Conflict of interest}

The author declares no conflict of interest.

\section{References}

1. Boyd TD. The Arch and the Vault in Greek Architecture. American Journal of Archaelogy. 1978;82(1):83-100.

2. Da Vinci L 1505. Foster Codex. 2:82v.

3. National Geographic (2014) news.nationalgeographic. com/ news/2014/02/140210-duomo-florence-brunelleschi-cathedralarchitecture

4. Romano A, Ochsendorf JA. The Mechanics of Gothic Masonry Arches. International Journal of Architectural Heritage. 2009;4(1):59-82.

5. Gil-Martín LM, Hernández-Montes E, Palomares A, et al. The optimum shape of an arch under non-symmetric loading conditions. Archive of Applied Mechanics. 2016;86(8):1509-1520.

6. Alexakis $\mathrm{H}$, Makris N. Limit equilibrium analysis of masonry arches. Arch Appl Mech. 2014;85(9):1363-1381.

7. Alexakis $\mathrm{H}$, Makris $\mathrm{N}$. Limit equilibrium analysis and the minimum thickness of circular masonry arches to withstand lateral inertial loading. Arch Appl Mech. 2014;84(5):757-772.

8. Hernández-Montes E, Fernández-Ruiz MA, Aschheim M, et al Structural knowledge within the 6th Century AD arch of Taq-i Kisra. International Journal of Architectural Heritage. 2017;11(6):891-900.

9. Villegas Cerredo D. Análisis estructural del patrimonio histórico. Spain: Torre del Homenaje de la Alhambra Master Thesis University of Granada; 2012. 72 p.

Figure 7 Scheme of the internally compensated weight per story. 